Quim. Nova, Vol. 36, No. 2, 314-319, 2013

\title{
BIOLUMINESCÊNCIA DE FUNGOS: DISTRIBUIÇÃO, FUNÇÃO E MECANISMO DE EMISSÃO DE LUZ
}

\author{
Anderson Garbuglio Oliveira \\ Departamento de Genética e Evolução, Universidade Federal de São Carlos, Rodovia João Leme dos Santos, km 110, 18052-780 \\ Sorocaba - SP, Brasil \\ Rodrigo Pimenta Carvalho, Hans Eugene Waldenmaier e Cassius Vinicius Stevani* \\ Departamento de Química Fundamental, Instituto de Química, Universidade de São Paulo, CP 26077, 05599-970 São Paulo - SP, \\ Brasil
}

Recebido em 7/5/12; aceito em 20/8/12; publicado na web em 6/2/13

\begin{abstract}
FUNGI BIOLUMINESCENCE: DISTRIBUTION, FUNCTION AND MECHANISM OF LIGHT EMISSION. The emission of light by living organisms, bioluminescence, has been studied since the nineteenth century. However, some bioluminescent systems, such as fungi, remain poorly understood. The emitter, the two enzymes involved, and the reaction mechanism have not yet been unraveled. Moreover, the ecological role and evolutionary significance for fungal luminescence is also unknown. It is hoped that comprehensive research on fungal bioluminescent systems will generate knowledge and tools for academic and applied sciences. This review discusses the distribution of bioluminescent fungi on Earth, attempts to elucidate the mechanism involved in light emission, and presents preliminary results on the evolution and ecological role of fungal bioluminescence.
\end{abstract}

Keywords: bioluminescent fungi; luciferin; luciferase.

\section{INTRODUÇÃO}

A emissão de luz por animais e plantas tem inspirado a curiosidade e o interesse da humanidade, sendo alvo de investigações por um grande número de naturalistas, físicos e fisiologistas, desde os tempos de Aristóteles (384-322 a.C.) e Plínio (23-79 d.C.). ${ }^{1}$ Bioluminescência, a emissão de luz fria e visível por seres vivos, é um fenômeno amplamente distribuído ao redor do mundo, sendo encontrada principalmente nos oceanos. Diversas espécies de bactérias, fungos, insetos, crustáceos, moluscos, celenterados, peixes, algas primitivas, vermes terrícolas e marinhos são descritos como bioluminescentes. ${ }^{2}$ Com relação à bioluminescência fúngica, existem diversos registros históricos sobre a emissão de luz de madeira e outros tipos de material celulósico em decomposição. Já no início, notou-se que a luz derivada dos materiais em decomposição não era acompanhada de calor. Além disso, a atenção dos cientistas da época estava mais voltada à emissão de luz propriamente dita, do que aos organismos que a emitiam. Somente no século XIX é que houve uma correlação entre causa e efeito, mencionando-se detalhes bioquímicos, como luciferina termoestável (substrato) e luciferase, para o fator lábil (enzimas), envolvidos na reação de emissão de luz. ${ }^{3}$

Em uma reação quimiluminescente forma-se um produto (emissor) no estado excitado, ao invés do estado fundamental. O retorno do emissor para o estado de menor energia é acompanhado pela emissão de luz. A formação do emissor no estado excitado é catalisada por uma enzima, genericamente chamada de luciferase, apesar da função e do tipo de reação catalítica das enzimas serem bastante diferentes. ${ }^{4} \mathrm{O}$ substrato da enzima, a luciferina, também tem estrutura molecular variada. Em alguns sistemas, como no caso de bactérias e fungos, existe a participação de mais uma enzima, uma redutase, na reação bioluminescente. Em águas-vivas, como a Aequorea victoria, a luciferina reage com oxigênio, formando um peróxido, o qual se liga covalentemente à enzima. ${ }^{5}$ Em todos os sistemas conhecidos o oxigênio é condição sine qua non para a reação acontecer. Sempre há formação de peróxidos, cíclicos ou não. Adicionalmente, não se deve

*e-mail: stevani@iq.usp.br confundir bioluminescência com quimiluminescência ultrafraca, que é um processo ligado ao estresse oxidativo (e.g., concentração elevada de $\mathrm{O}_{2}$ ou presença de espécies reativas de oxigênio) e que envolve a emissão de luz por oxigênio singlete, estados tripletes, peróxinitrito, lipoperoxidação, reação entre heme proteínas e peróxidos. ${ }^{5,6}$

Apesar dos avanços significativos ocorridos nas últimas décadas, que forneceram ferramentas para a ampliação do conhecimento sobre a ocorrência, taxonomia, filogenia e ecologia de fungos bioluminescentes, pouco se avançou no que se diz respeito ao entendimento da bioquímica envolvida na emissão de luz dos fungos. ${ }^{7,8}$ Recentemente, Oliveira e Stevani comprovaram que a bioluminescência fúngica realmente depende de uma redutase e de uma luciferase, como proposto na década de 1960 por Airth e Foerster.,10 Os autores confirmaram que o processo de emissão de luz depende de duas enzimas, uma solúvel e dependente de NADPH (fosfato de nicotinamida adenina dinucleotídeo reduzida) ou NADH (nicotinamida adenina dinucleotídeo reduzida ) e outra insolúvel, com função catalítica sobre a emissão de luz (portanto, uma luciferase). A luciferina fúngica reage inicialmente com uma redutase dependente de NADPH e, em seguida, com a luciferase fúngica, resultando na emissão de luz, muito similar ao que ocorre em bactérias ${ }^{9}$ (Figura 1).

Também foi comprovado que as enzimas, bem como os substratos, eram os mesmos para todas as quatro linhagens de fungos bioluminescentes conhecidas: Armillaria, Lucentipes, Micenoide e Omphalotus (Figura 1S, material suplementar).

Em relação às enzimas (redutase e luciferase) envolvidas na reação de emissão de luz de fungos, foram executadas tentativas de purificação durante a década de 1960 , porém sem sucesso. ${ }^{11,12}$ Todavia, no caso de bactérias bioluminescentes, cujo mecanismo de emissão de luz é semelhante ao dos fungos, a purificação das enzimas envolvidas no processo de emissão de luz foi realizada com sucesso ainda durante a década de $1970 .{ }^{13}$ Dessa maneira, esse sistema poderá servir como um excelente ponto de partida para o isolamento das enzimas em fungos. Especificamente, com relação à luciferase fúngica, acredita-se que devido a sua natureza insolúvel, esteja associada a alguma membrana, fato que dificulta a sua purificação. Espera-se que com a purificação de seus componentes, o sistema de bioluminescência em 
Bioluminescência de fungos - Proposta de Airth \& Foerster

$$
\begin{array}{r}
\mathrm{L}+\mathrm{NAD}(\mathrm{P}) \mathrm{H}+\mathrm{H}^{+} \frac{\text { enzima solúvel }}{\text { (redutase) }}-\mathrm{LH}_{2}+\mathrm{NAD}(\mathrm{P})^{+} \\
\mathrm{LH}_{2}+\mathrm{O}_{2} \frac{\text { enzima insolúvel }}{\text { (luciferase) }} \mathrm{LO}+\mathrm{H}_{2} \mathrm{O}+\mathrm{hv}
\end{array}
$$

$\mathrm{L}$ : luciferina, $\mathrm{LH}_{2}$ : luciferina reduzida, $\mathrm{LO}$ : oxiluciferina

\section{Bioluminescência de bactérias}

$$
\begin{aligned}
& \mathrm{FMN}+\mathrm{NAD}(\mathrm{P}) \mathrm{H}+\mathrm{H}^{+} \stackrel{\text { redutase }}{\longrightarrow} \mathrm{FMNH}_{2}+\mathrm{NAD}(\mathrm{P})^{+} \\
& \mathrm{FMNH}_{2}+\mathrm{RCHO}+\mathrm{O}_{2} \stackrel{\text { luciferase }}{\longrightarrow} \mathrm{FMN}+\mathrm{RCO}_{2} \mathrm{H}+\mathrm{H}_{2} \mathrm{O}+\mathrm{hv}
\end{aligned}
$$

FMN: flavina mononucleotideo oxidada (luciferina), $\mathrm{FMNH}_{2}$ : FMN reduzida $\mathrm{RCHO}$ : aldeído alifático de cadeia longa, $\mathrm{RCO}_{2} \mathrm{H}$ : ácido graxo

Figura 1. Mecanismo de emissão de luz em fungos, proposto por Airth e Foerster na década de 1960 e o mecanismo em bactérias

fungos abra novas perspectivas de estudos acadêmicos e aplicados, podendo contribuir como um novo e importante modelo de estudos enzimáticos e de transporte e regulação na membrana celular.

\section{DISTRIBUIÇÃO DAS ESPÉCIES E FUNÇÃO ECOLÓGICA}

Existem 71 espécies conhecidas de fungos bioluminescentes, divididas em quatro linhagens, Armillaria, Omphalotus, Micenoide e Lucentipes, onde 52 são Micenoides (73\%), 4 Armillaria (6\%), 13 Omphalotus (18\%) e 2 Lucentipes (3\%). Das 71 espécies descritas, 12 espécies podem ser encontradas no Brasil (17\%), sendo que pelo menos 8 eram desconhecidas da comunidade científica. ${ }^{7,8,14,15}$ Os corpos de frutificação foram encontrados nos estados do Paraná, São Paulo, Mato Grosso do Sul, Piauí, Tocantins, Goiás, Maranhão e Amazonas (Figura 2). A América do Sul não possui a linhagem Armillaria, presente somente em América do Norte, Ásia e Europa. Já a linhagem recém-proposta, Lucentipes, só existe nas Américas Central e do Sul. As espécies estão distribuídas pela América do Norte (28\% das 71), Central (10\%), do Sul (30\%), Europa (30\%), Ásia (52\%), Oceania (18\%) e África (10\%).
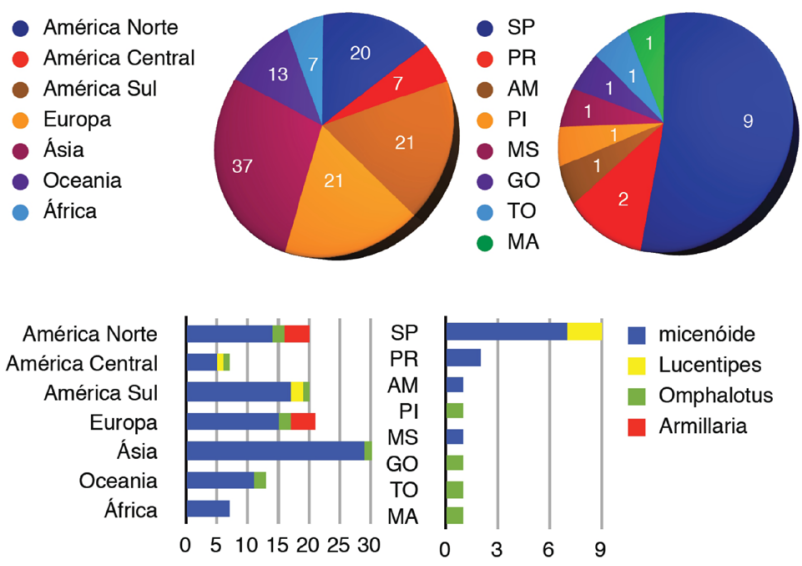

Figura 2. Distribuição das 71 espécies de fungos bioluminescentes existentes no Brasil e no mundo até 2012

Fungos bioluminescentes podem ser encontrados em diversas florestas tropicais e temperadas do mundo. Desde que a temperatura seja amena $\left(20-30{ }^{\circ} \mathrm{C}\right)$, a umidade seja elevada e haja material lignocelulósico em decomposição, estes fungos podem ser encontrados desde pequenas matas ciliares até na Floresta Amazônica (Figura 3). Nove espécies de fungos bioluminescentes, Gerronema viridilucens, Mycena lucentipes, Mycena asterina, Mycena fera (variação branca e negra), Mycena singeri, Mycena discobasis, Mycena luxaeterna, Mycena aff. abieticola e uma Mycena sp. desconhecida, foram encontradas no Parque Estadual Turístico do Alto Ribeira (PETAR), no Bairro da Serra, município de Iporanga, SP. ${ }^{16,17}$ A espécie Mycena lacrimans foi descoberta no Amazonas; a Mycena luxarboricola, no Paraná e o fungo Neonothopanus gardneri, no Piauí, Tocantins, Goiás e Maranhão (Figura 2S, material suplementar). ${ }^{15,18,19}$

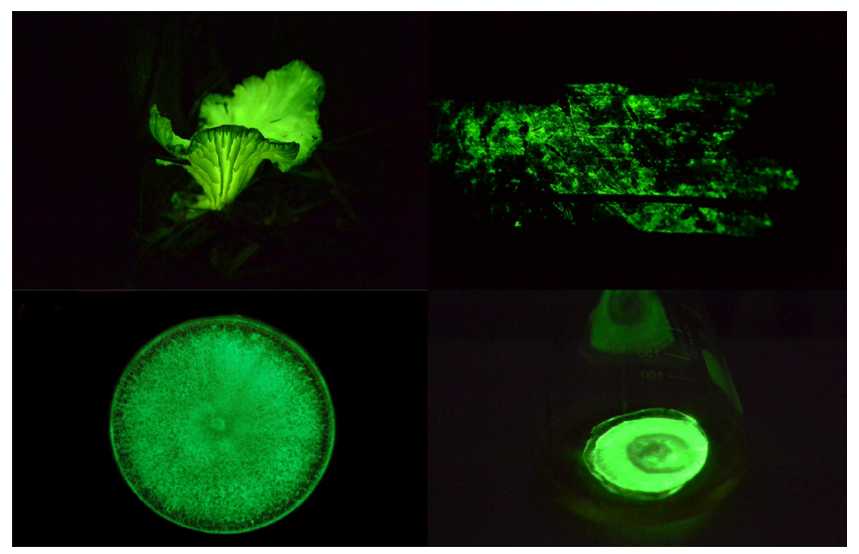

Figura 3. Fungos bioluminescentes podem ser encontrados na forma de corpos de frutificação ou micélio sobre material em decomposição na natureza, cultivados em laboratório em placa de Petri com ágar ou em meio líquido

Tendo em vista que três dezenas de espécies bioluminescentes de Mycenas estão espalhadas em mais de 16 seções, surge a pergunta: a bioluminescência (BL) de fungos evoluiu independentemente na linhagem Micenoide inúmeras vezes ou somente uma vez (ou poucas vezes), em um passado remoto, e se perdeu inúmeras vezes? ${ }^{17}$ Presume-se, portanto, que esse sistema bioluminescente é utilizado para um importante papel biológico e bioquímico e que evoluiu precocemente na história evolucionária desta linhagem, perdendo-se inúmeras vezes e reaparecendo.

São fortes as evidências de que a bioluminescência também desempenhe um papel de proteção antioxidante frente à ação deletéria das espécies reativas de oxigênio. McElroy e Seliger propuseram, em 1962, que a bioluminescência teria evoluído de um mecanismo ancestral de desintoxicação, com único e exclusivo propósito de consumir oxigênio. ${ }^{17,20}$ Seliger, em 1975 , foi o primeiro a sugerir que as luciferases surgiram de oxigenases de função mista, envolvidas na remoção de compostos insaturados durante os primeiros momentos de vida na Terra. ${ }^{17,21}$ Wood propôs em 1995, de forma contrária, que o fenótipo luminescente dirigiu a evolução das luciferases para a nova função oxigenásica. ${ }^{22} \mathrm{Na}$ bactéria bioluminescente Xenorhabdus luminescens sob hiperóxia ocorre concomitante indução das enzimas antioxidante superóxido dismutase e luciferase. Há relatos do possível papel das luciferinas como moléculas antioxidantes na água-viva, Aequorea sp., e no pirilampo, Pyrearinus termitilluminans. ${ }^{5}$

É importante lembrar que o entendimento da bioluminescência de fungos não seria completo sem avaliar a significância ecológica dela para o organismo. Em outros sistemas, é relativamente fácil entender as vantagens seletivas da bioluminescência, como a atração do(a) parceiro(a), em vagalumes, ou a relação simbionte entre bactérias bioluminescentes (Vibrio fischeri) e peixes. Diversos possíveis papéis ecológicos para os fungos bioluminescentes foram propostos por Sivinski: ${ }^{23}$ i) atrair dispersores de esporos, ii) atração de carnívoros e fungívoros, iii) atração de fertilizadores, iv) repulsão de fungívoros fotofóbicos, v) atração de fungívoros e outros competidores fúngicos e vi) luz como sinal de alerta da toxicidade do fungo.

É certo que a bioluminescência atrai a atenção de certos artrópodes. ${ }^{23}$ Muitos deles são conhecidos por serem fototrópicos, pois 
são atraídos por luzes diversas, incluindo a iluminação urbana. Há exemplos de espécies bioluminescentes de Collembola, Hemiptera, Coleoptera e Diptera. ${ }^{5}$ Larvas luminescentes de moscas da família Mycetophilidae usam sua bioluminescência para atrair presas fototrópicas para suas "teias" (i.e., fios pendurados no teto da caverna compostos de material pegajoso). Adicionalmente, a perturbação da larva ou pupa acarreta em emissão de luz, a qual pode agir como sinal de advertência para predadores fotofóbicos. ${ }^{24,25}$ Por outro lado, vagalumes e outros artrópodes bioluminescentes são atacados por moscas parasitas das famílias Phoridae e Tachinidae. ${ }^{26}$ A bioluminescência no filo Arthropoda é usada para mostrar muitos comportamentos agressivos e sexuais. É provável que a bioluminescência fúngica tenha impacto significante na emissão de luz por artrópodes, sendo que as espécies evoluíram certamente tendo benefícios mútuos.

Sivinski usou tubos de ensaio selados e frascos de vidro, folhas e galhos em decomposição cobertos pelo micélio bioluminescente e corpos de frutificação do fungo Dictyopanus pusillus, para comprovar suas hipóteses de função da luminescência. Corpos de frutificação não luminescentes foram usados como controle. ${ }^{23}$ As "armadilhas" foram deixadas à noite em áreas onde o micélio e os corpos de frutificação foram encontrados. Os espécimes capturados foram coletados na manhã seguinte, aderidos na superfície, e catalogados. Os resultados deste estudo mostraram que mais artrópodes foram capturados nas armadilhas com micélio e corpos de frutificação bioluminescentes do que nos controles. Collembola e Diptera foram significativamente mais abundantes nas armadilhas luminosas. Já predadores, tais como, aranhas, formigas e tesourinhas (dermápteros) foram encontradas nas armadilhas bioluminescentes em número beirando a significância estatística.

Acredita-se que a principal função biológica da emissão de luz por fungos seja a de atrair insetos dispersores de esporos, o que ocorre em fungos não bioluminescentes, como em algumas espécies de fungos fétidos da família Phallales, que atraem moscas. ${ }^{24}$ Pequenos mosquitos (e. g. Phoridae, Diptera) e Collembola são coletados em maior abundância em armadilhas utilizando o fungo luminoso Dictyopannus pusillus (Lev.) do que em outras com espécies não bioluminescentes. ${ }^{23}$ No fungo Mycena pruinosa-visida (Corner) e $M$. rorida (Fr.) Quel., dos trópicos orientais, somente os esporos emitem luz; na maioria dos corpos de frutificação, a emissão de luz é restrita ou mais intensa nas lamelas e o fungo Panellus stipticus emite luz mais intensa no período que os esporos estão na maturação. ${ }^{24} \mathrm{~A}$ localização da emissão nos corpos de frutificação e interações crescentes com insetos refuta o argumento de que a bioluminescência em fungos não tem função, ou seja, é consequência inútil de um subproduto do metabolismo fúngico. ${ }^{23}$

\section{MECANISMO DE BIOLUMINESCÊNCIA}

\section{Explorações iniciais}

Considera-se que o moderno estudo da bioluminescência começou quando Dubois demonstrou o primeiro exemplo de reação luciferina/luciferase, em 1885, através da preparação de dois extratos a partir dos órgãos luminosos do besouro Pyrophorus noctilucus. ${ }^{27}$ Um desses extratos foi preparado em água gelada, resultando em uma suspensão luminosa. Essa luminescência decresceu gradualmente e finalmente desapareceu. O segundo extrato foi preparado inicialmente usando água quente, o que imediatamente suprimiu a luz, e depois resfriado. Quando os extratos quente e frio foram combinados, a emissão de luz foi restabelecida. Dubois também observou o mesmo comportamento utilizando extratos feitos a partir do vôngole Pholas dactylus. ${ }^{28}$ Ele concluiu que o extrato frio era composto por uma fração proteica, termo-lábil, necessária para a emissão de luz que chamou de "luciferase". No extrato quente, onde as proteínas haviam sido desnaturadas pelo calor, haveria uma substância relativamente termo-estável que designou como "luciférine". Assim, uma reação luciferina/luciferase, poderia ser vista como uma reação substrato/ enzima que resultava em emissão de luz.

De maneira geral, o sistema bioluminescente de um organismo pode envolver uma série de reações químicas, embora a luz seja emitida apenas a partir de uma reação que produz um estado excitado do emissor. Apesar de existirem diversas sistemas bioluminescentes, todos envolvem a oxidação de um substrato (usualmente chamado de luciferina), por sua luciferase ou uma fotoproteína. Toda bioluminescência é uma reação quimiluminescente. ${ }^{5,29}$

Com relação à bioluminescência fúngica, as primeiras tentativas para elucidar o mecanismo químico de emissão de luz em fungos foram baseadas no clássico procedimento de Dubois, descrito em 1885. A dependência de oxigênio molecular para a emissão já era conhecida. ${ }^{7,30}$ Se a emissão de luz a partir dos extratos fosse muito fraca para ser percebida a olho nu, haveria a necessidade de um fotômetro sensível ou photocounter, indisponível na época. Talvez isso explique as tentativas mal sucedidas de Ewart, em 1907, e de Kawamura, em 1915, para detectar a luz usando o extrato frio e o extrato quente dos fungos Pleurotus candescens e Omphalotus japonicus, respectivamente. Alguns anos mais tarde, Harvey aplicou o procedimento de Dubois, utilizando os fungos Armillaria mellea, Omphalotus olearius e Panellus stipticus, mas não observou nenhuma emissão de luz, resultado esse atribuído à baixa concentração e instabilidade da luciferina ou luciferase nos extratos..$^{1,7}$

Buller tentou extrair a luciferina/luciferase do fungo Panellus stipticus, pressionando os basidiomas entre duas placas de vidro. Como os cogumelos foram gradualmente espremidos, a emissão de luz diminuiu até a extinção total. A luz podia também ser detectada visualmente se algumas gotas de água fossem adicionadas sobre cogumelos secos e inteiros. No entanto, se cogumelos secos fosse pulverizados, a luz não era mais observada com a adição de água. Buller interpretou esses resultados como a inativação química das substâncias envolvidas na reação bioluminescente, tais como a oxidação da luciferina e/ou da luciferase por substâncias anteriormente confinadas em compartimentos da célula. ${ }^{31}$

Em 1959, Airth e McElroy finalmente realizaram uma experiência bem-sucedida com o extrato frio e o extrato quente. Como Harvey, eles atribuíram o fracasso das tentativas anteriores à baixa concentração de luciferase nos extratos, além da eventual presença de inibidores e/ou à labilidade da luciferina no extrato quente. O resultado obtido mais importante foi o de que a emissão de luz só podia ser detectada se NADPH ou NADH fosse adicionado ao meio reativo. ${ }^{32}$

\section{Proposta de Airth e Foerster}

Airth e Foerster realizaram diversos experimentos bioquímicos com o intuito de esclarecer o mecanismo de emissão de luz em fungos. Duas espécies de cogumelos bioluminescentes foram preferencialmente estudadas: Armillaria mellea, um conhecido fungo patogênico que ataca raízes de plantas, e Collybia velutipes. Além de evidenciarem que o processo de emissão de luz dependia de duas enzimas, uma solúvel e dependente de NADPH (portanto, uma redutase) e outra de membrana, com função catalítica sobre a emissão de luz (portanto, uma luciferase - classe de enzimas que catalisam reações bioluminescentes), os autores observaram que as enzimas, bem como os substratos, eram os mesmos para os dois fungos utilizados. Usando Armillaria mellea como fonte de substrato e Collybia velutipes como fonte das enzimas, foi possível observar emissão de luz. ${ }^{12}$

O procedimento experimental consistia primeiramente em se preparar um extrato em água fervente com um dos cogumelos secos, 
a fim de se obter a luciferina fúngica. Em seguida, um homogenato com o outro cogumelo, também seco, era preparado a frio e fracionado por ultracentrifugação, com o intuito de isolar a redutase, presente na parte solúvel, e a luciferase, presente no precipitado. A emissão de luz podia ser observada quando o extrato quente, contendo a luciferina, era misturado com a redutase na presença de $\mathrm{NAD}(\mathrm{P}) \mathrm{H}$, seguido da adição da luciferase, após alguns minutos de incubação. Quanto maior o tempo de incubação ou a quantidade de enzima redutase, maior a intensidade de emissão. Nesta proposta, a luciferina fúngica reage inicialmente com uma redutase dependente de NADPH e, em seguida, com a luciferase fúngica, resultando na emissão de luz.

Apesar da proposta de Airth e Foerster se assemelhar à da bioluminescência bacteriana (Figura 1), o sistema de fungos não é estimulado pela adição de flavina mononucleótido reduzida $\left(\mathrm{FMNH}_{2}\right)$, flavina adenina reduzida $\left(\mathrm{FADH}_{2}\right)$, na presença ou ausência de dodecanal. Além disso, outros derivados de flavinas testados como riboflavina, lumicromo, aloxazina e lumazina, também não levaram à emissão de luz, observada com o auxílio de um luminômetro de tubo bastante sensível. Outra diferença do sistema de bactérias é que o comprimento de onda de emissão máxima, observado para a bioluminescência de fungos é de ca. $530 \mathrm{~nm}$, enquanto que para as bactérias é de ca. 490 nm. ${ }^{4}$ Além disso, os autores repetiram com sucesso a experiência com qualquer combinação possível de extrato quente e frio, dos fungos Armillaria mellea e Collybia velutipes, e da variedade bioluminescente norte-americana de Panellus stipticus, sugerindo que tanto as enzimas quanto o substrato eram essencialmente os mesmos para todos os fungos bioluminescentes. ${ }^{12}$

Entretanto, a caracterização estrutural dos componentes químicos nunca foi realizada com sucesso. Todos os esforços realizados para purificar as frações de proteínas, utilizando precipitação com sulfato de amônio, diálise, diferentes tipos de cromatografia e centrifugação diferencial, resultaram na perda da atividade e degradação proteica. No que diz respeito à purificação da luciferina, sua instabilidade, especialmente em presença de oxigênio molecular, dificultava a adoção de procedimentos de purificação e caracterização estrutural posteriores. Em 1966, Kuwabara e Wassink foram capazes de isolar $12 \mathrm{mg}$ de uma substância cristalina fluorescente a partir de $15 \mathrm{~kg}$ de micélio cultivado do fungo Mycena citricolor ${ }^{33} \mathrm{O}$ composto era instável em condições básicas, na presença de luz e oxigênio molecular $\mathrm{e}$, em altas temperaturas, semelhante ao que foi relatado para outras luciferinas isoladas de diferentes organismos bioluminescentes. Além disso, a emissão de luz visível verde, com um espectro similar ao da bioluminescência de fungos foi observada na presença de $\mathrm{NaOH}$ e $\mathrm{H}_{2} \mathrm{O}_{2}$, ou quando a substância foi submetida ao procedimento descrito por Airth e Foerster. Infelizmente, os autores nunca relataram propriedades estruturais ou físico-químicas da substância fluorescente cristalina isolada. ${ }^{33}$

Entre o início dos anos 1970 e meados dos anos 1990, alguns autores afirmaram ter sido capazes de isolar e caracterizar a estrutura química da luciferina de fungos. Entre as moléculas isoladas podem-se citar: iludina S, ergosta-4,6,8(14),22-tetraen-3-ona, riboflavina e a lampteroflavina, todas extraídas e purificadas a partir do fungo $P$. japonicus (Figura 4). ${ }^{34-39}$ Não obstante as semelhanças dos espectros de fluorescência destas moléculas com o observado para a bioluminescência de fungos, nenhuma prova adicional foi apresentada desde então, que apoiasse o envolvimento de qualquer uma destas moléculas no mecanismo de emissão de luz de fungos in vivo. Ademais, considerando que fungos bioluminescentes podem conter vários compostos fluorescentes e que o espectro de emissão de alguns deles podem ser similares ao espectro de bioluminescência, uma coincidência espectral é apenas uma condição marginal de que o composto isolado poderia ser o emissor de luz na bioluminescência fúngica. Assim, é importante demonstrar que um determinado composto isolado está envolvido na reação de emissão de luz.

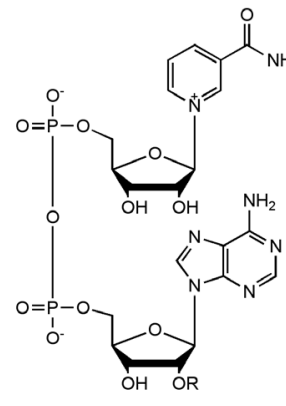

$\mathrm{R}=\mathrm{H}, \mathrm{NADH}$ $\mathrm{R}=\mathrm{PO}_{3^{2}}$, NADPH

$R=H$, panal

$\mathrm{CO}\left(\mathrm{CH}_{2}\right)_{8} \mathrm{CH}_{3}$, PSA

$\mathrm{CO}\left(\mathrm{CH}_{2}\right)_{10} \mathrm{CH}_{3}, \mathrm{PSB}$

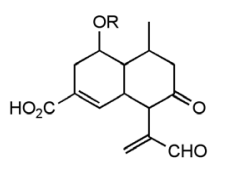

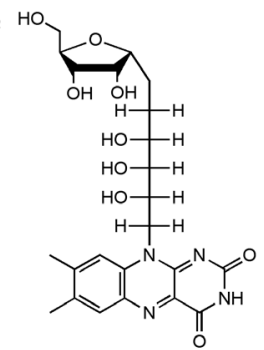

lampteroflavina

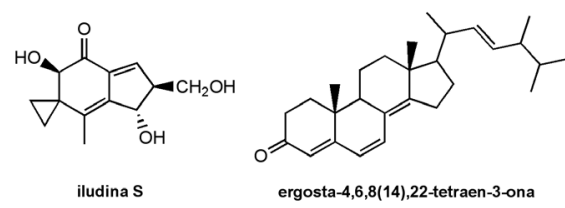

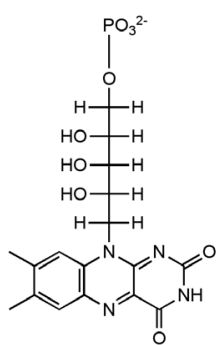

flavina mononucleotideo
Figura 4. Estruturas químicas das moléculas de NADPH, NADH, lampteroflavina, FMN, panal, iludina $S$ e ergostatetraenona

\section{Prosposta de Shimomura}

Shimomura relatou que extratos preparados com o fungo bioluminescente $P$. stipticus não emitiam luz, segundo o procedimento descrito por Airth e Foerster, concluindo que, ou este fungo apresentava um mecanismo peculiar de emissão independente de enzimas, ou o mecanismo desses autores não contemplava todas as etapas necessárias para explicar o mecanismo de emissão.?

No final da década de 1980, Nakamura e colaboradores isolaram um sesquiterpeno do cogumelo Panellus stipticus, denominado panal, e formularam uma nova proposta não enzimática para a bioluminescência fúngica. ${ }^{40,41} \mathrm{Nesta}$ proposta, o panal é a molécula precursora da luciferina. Duas outras substâncias foram isoladas posteriormente, o PS-A e o PS-B, identificados como os ésteres decanoico e dodecanoico do panal, respectivamente. O procedimento para a obtenção da luciferina, segundo os autores, consistia em manter o panal de 12 a 16 h na presença de sulfato de amônio ou de uma amina primária e de brometo de cetiltrimetilamônio (CTAB), em pH 3,7 e a $25^{\circ} \mathrm{C}$. Após a adição de $\mathrm{Fe}^{2+} / \mathrm{H}_{2} \mathrm{O}_{2}$, em pH 7-8 observava-se emissão de luz. Dependendo do surfactante utilizado no meio reacional a luz final emitida variava de comprimento de onda entre $485-585 \mathrm{~nm} .{ }^{42}$ Os autores propuseram um mecanismo sem envolvimento de enzimas, pelo menos na etapa de emissão, não excluindo, entretanto, a possibilidade de que alguma etapa enzimática seja responsável pela "ativação" da luciferina fúngica. É interessante esclarecer que não há nenhum indício de reação do panal com algum composto nitrogenado in vivo para formar a luciferina fúngica. No caso do panal, supôs-se que a reação com aminas também aconteceria, levando à formação de uma molécula mais rígida e, consequentemente, mais fluorescente. $\mathrm{O}$ panal é pouco conjugado e bastante flexível, havendo realmente a necessidade de uma reação de ciclização que o torne mais rígido, para que possa ser o emissor. Além disso, sabe-se que o radical hidroxila produzido pela reação de Fenton $\left(\mathrm{Fe}^{2+}\right.$ na presença de $\mathrm{H}_{2} \mathrm{O}_{2}$ ) é extremamente reativo e inespecífico, não contribuindo para o estabelecimento de uma condição fisiológica compatível com o que seria de se esperar em reações desse tipo. Dessa maneira, a hipótese de um mecanismo 
não enzimático envolvido na bioluminescência fúngica requer investigações mais profundas para ser considerada válida.

\section{RESULTADOS ATUAIS E PERSPECTIVAS}

Apesar dos diversos trabalhos sobre fungos bioluminescentes publicados nos últimos 50 anos, apenas modestos avanços foram feitos na investigação acerca do mecanismo de bioluminescência fúngica. Sem dúvida, um dos pontos de maior divergência no mecanismo de bioluminescência de fungos sempre foi a existência ou não de enzimas envolvidas no processo. As duas principais propostas defendidas até 2009, como já mencionado, eram a enzimática, de Airth e Foerster, da década de 1960, e a não enzimática, de Shimomura, do final da década de 1980.

Em 2009, entretanto, Oliveira e Stevani corroboraram a hipótese enzimática, verificando que, de fato, as principais falhas descritivas nos ensaios de Airth e Foerster eram alta labilidade da luciferina, concentrações extremamente baixas de luciferase ativa e necessidade de cofatores e coenzimas como, por exemplo, NAD $(\mathrm{P}) \mathrm{H}$. Airth e Foerster fundamentaram-se na metodologia de Dubois, porém com modificações experimentais para evitar a degradação dos componentes envolvidos e obter emissão de luz enzimaticamente.

Se o extrato frio realmente contém enzimas responsáveis pela oxidação do substrato (presente no extrato quente), ou seja, a reação é enzimática, então, variando-se a concentração de enzimas (extrato frio) a cinética da reação (avaliada pelas constantes de velocidade observada) deveria ser alterada, enquanto a quantidade de luz total emitida (avaliada pela integral do gráfico) deveria ser constante. Por sua vez, a variação na quantidade de substrato (extrato quente) só deveria causar aumento na luz emitida, sem alterar a cinética, pois a quantidade de enzimas é sempre a mesma. Os resultados obtidos com os corpos de frutificação do fungo $G$. viridilucens, como fonte de extrato quente, e o micélio, como fonte do extrato frio, corroboram as afirmações acima. ${ }^{9}$

Ainda segundo a proposta enzimática de Airth e Foerster, no processo de emissão de luz estaria envolvida uma proteína solúvel [uma redutase, $\mathrm{NAD}(\mathrm{P}) \mathrm{H}$-dependente] e uma proteína insolúvel, presente no pellet, catalisadora da reação (luciferase). Através de ultracentrifugação e seguindo metodologia similar à de Airth e Foerster, foi possível separar do extrato frio o sobrenadante (fração solúvel) e o pellet (fração insolúvel). Experimentos de emissão de luz utilizando essas duas frações proteicas mostram resultados interessantes. Necessariamente, ambas as frações são requeridas para que a emissão de luz máxima seja alcançada. Além disso, a ordem de adição das frações altera a cinética da reação. Provavelmente essa variação na cinética ocorre porque quando a fração solúvel (redutase) é adicionada inicialmente, há um tempo breve no qual ocorre a produção e o acúmulo da luciferina em sua forma reduzida, que depois é rapidamente consumida quando se adiciona a fração insolúvel (luciferase). Caso a ordem de adição seja invertida, qualquer luciferina reduzida é prontamente oxidada levando à emissão de luz (Figura 1). Esses resultados confirmaram a proposta enzimática de Airth e Foerster em relação à não enzimática de Shimomura. A proposta enzimática é biologicamente compatível por usar condições mais brandas do que as empregadas na proposta de Shimomura. Adicionalmente, o espectro de quimiluminescência obtido nas reações in vitro $\left(\lambda_{\text {máx }}=538 \mathrm{~nm}\right)$ é muito similar ao da bioluminescência do fungo $\lambda_{\text {máx }}=530 \mathrm{~nm}$ ). ${ }^{9}$

Ensaios preliminares de purificação das enzimas mostram que tanto a redutase quanto a luciferase possuem massa entre 100 e 300 $\mathrm{kDa}$. As duas foram purificadas parcialmente por ultracentrifugação, cromatografia de afinidade e troca iônica. A redutase parece ser uma flavoproteína, visto que durante seu processo de purificação essa enzima perde atividade rapidamente, e somente a incubação desta na presença de FMN (flavina mononucleotídeo) é capaz de restaurá-la.

Finalmente, evidências de um substrato comum e enzimas nas quatro linhagens evolutivas de fungos bioluminescentes apoiariam a hipótese do envolvimento do mesmo mecanismo enzimático em todas as espécies conhecidas, sugerindo ainda uma única origem inicial da bioluminescência na ordem Agaricales de espécies formadoras de cogumelos. Dados com os extratos quente e frio sustentam a hipótese de um mecanismo enzimático único em todas as linhagens de fungos bioluminescentes conhecidos, uma vez que a presença da luciferina no extrato quente e enzimas no extrato frio são condição sine qua non para se observar emissão de luz. Além disso, pode-se também concluir que a luciferina, as enzimas e o emissor são semelhantes em cada linhagem. Estes resultados indicam uma única origem evolutiva da via bioluminescentes na ordem Agaricales, e sugerem que esta via se tornou inativa, perdida ou não reconhecida em um grande número de táxons. ${ }^{8}$

\section{CONCLUSÕES}

A quimiluminescência e a bioluminescência são processos extremamente interessantes e importantes dos pontos de vista acadêmicos e aplicados, pois constituem modelos bastante interessantes para as mais diversas investigações multidisciplinares, tais como, estudos mecanísticos de conversão de energia química, ${ }^{43,44}$ estrutura e função de proteínas, evolução enzimática, fotoecologia e material educacional. ${ }^{45,46}$ As luciferases e luciferinas conhecidas hoje são utilizadas amplamente para finalidades bioanalíticas nas áreas médica (diagnósticos e estudos pré-clínicos de patologias como infecções bacterianas, virais e câncer), biotecnológica (biossensores luminescentes) e ambiental (bioensaios/biossensores de toxicidade). ${ }^{47,48}$ Todas estas aplicações utilizam ainda umas poucas luciferases oriundas de bactérias, fotoproteínas de celenterados, crustáceos e de vagalumes. ${ }^{2}$

Dessa maneira, a compreensão do mecanismo e da natureza dos constituintes envolvidos no processo de emissão de luz em fungos abrirá novas perspectivas de estudos acadêmicos e aplicados. $\mathrm{O}$ fato de a luciferase fúngica ser, muito provavelmente, uma proteína de membrana poderá contribuir como um novo e importante modelo de estudos enzimáticos, de transporte e regulação na membrana celular. Finalmente, a clonagem da luciferase fúngica é essencial para iniciar os estudos de estrutura e função da luciferase deste novo sistema e, consequentemente, dos seus mecanismos bioquímicos, para compreender a origem evolutiva do sistema bioluminescente de fungos e, possivelmente, para aplicar este novo sistema para fins bioanalíticos.

\section{MATERIAL SUPLEMENTAR}

Disponível em http://quimicanova.sbq.org.br, em arquivo pdf com acesso livre. Na Figura 1S são mostradas fotos de corpos de frutificação das quatro linhagens conhecidas de fungos bioluminescentes (Armillaria, Lucentipes, Micenoide e Omphalotus). A Figura $2 \mathrm{~S}$ apresenta fotos das 12 espécies de fungos bioluminescentes encontradas no Brasil durante o período de 2002-2012.

\section{AGRADECIMENTOS}

À Fundação de Amparo à Pesquisa do Estado de São Paulo (FAPESP) pelo apoio financeiro, ao Instituto de Química da Universidade de São Paulo e ao Núcleo Avançado de Pesquisa em Fotoquímica da USP (NAP PhotoTech) pela infraestrutura.

\section{REFERÊNCIAS}

1. Harvey, E. N.; Bioluminescence, Academic Press: New York, 1952. 
2. Waldenmaier, H. E.; Oliveira, A. G.; Stevani, C. V.; Int. J. Astrobiol. 2012, 11, 335 .

3. Harvey, E. N.; A History of Luminescence from Ancient Times to 1900, J. H. Furst Company: Baltimore, 1957.

4. Wilson, T.; Hastings, J. W.; Annu. Rev. Cell Dev. Biol. 1998, 14, 197.

5. Shimomura, O.; Bioluminescence - Chemical Principles and Methods, World Scientific Publishing Co. Pte. Lt.: Singapore, 2006.

6. Halliwell, B.: Gutterridge, J. M. C.; Free Radicals in Biology and Medicine, $4^{\text {th }}$ ed., Oxford University Press: Oxford, 2007.

7. Desjardin, D. E.; Oliveira, A. G.; Stevani, C. V.; Photochem. Photobiol. Sci. 2008, 7, 170.

8. Oliveira, A. G.; Desjardin, D. E.; Perry, B. A.; Stevani C. V.; Photochem. Photobiol. Sci. 2012, 11, 848.

9. Oliveira, A. G.; Stevani, C. V.; Photochem. Photobiol. Sci. 2009, 8, 1416.

10. Airth, R. L.: Foerster, G.: Behrens, Q. P. Em Bioluminescence in Progress; Johnson, F. H.; Haneda Y., eds.; Princeton University Press: New Jersey, 1966.

11. Airth, R. L.; Foerster, G. E.; Arch. Biochem. Biophys. 1962, 97, 567.

12. Airth, R. L.; Foerster, G. E.; J. Bacteriol. 1964, 88, 1372.

13. Jablonski, E.; DeLuca, M.; Biochemistry 1977, 16, 2932.

14. Desjardin, D. E.; Perry, B. A.; Lodge, D. J.; Stevani, C. V.; Nagasawa, E.; Mycologia 2010, 102, 459.

15. Stevani, C. V.; Oliveira, A. G.; Mendes, L. F.; Luminescence 2006, 21, 292.

16. Desjardin, D. E.; Capelari, M.; Stevani, C. V.; Fungal Divers. 2005, 18, 9.

17. Desjardin, D. E.; Capelari, M.; Stevani, C. V.; Mycologia 2007, 99, 317.

18. Desjardin, D. E.; Braga-Neto, R.; Edinburgh J. Bot. 2007, 64, 275.

19. Capelari, M.; Desjardin, D. E.; Perry, B. A.; Asai, T.; Stevani ,C. V.; Mycologia 2011, 106, 1433.

20. McElroy, W. D.: Seliger, H. H. Em Origin and Evolution of Bioluminescence; Kasha M.; Pullman B., eds.; Academic Press: New York, 1962.

21. Seliger, H. H.; Photochem. Photobiol. 1975, 21, 355.

22. Wood, K. V.; Photochem. Photobiol. 1995, 62, 662.

23. Sivinski, J.; Psyche 1981, 88, 383.
24. Sivinski, J.; Aluja, M.; Holler, T.; Eitam, A.; Environ. Entomol. 1998, 27,360 .

25. Gatenby, J. B.; Trans. R. Soc. N. Z. 1959, 8, 149.

26. Lloyd, J. E.; Florida Entomol. 1974, 57, 90.

27. Dubois, R.; C. R. Soc. Biol. 1885, 37, 559.

28. Dubois, R.; C. R. Soc. Biol. 1887, 39, 564.

29. Campbell, A. K.; Chemiluminescence - Principles and Applications in Biology and Medicine, VCH: Chichester, 1988.

30. Hastings, J. W.; J. Cell Comp. Physiol. 1952, 39, 1.

31. Buller, A. H. R.; Researches on Fungi, Longmans, Green and Co.: London, New York, 1924.

32. Airth, R. L.; McElroy, W. D.; J. Bacteriol. 1959, 77, 249.

33. Kuwabara, S.: Wassink, E. C. Em ref. 10.

34. Endo, M.; Kajiwara, M.; Nakanishi, K.; Chem. Commun. 1970, 309.

35. Isobe, M.; Uyakul, D.; Goto, T.; J. Biolumin. Chemilumin. 1987, 1, 181.

36. Isobe, M.; Takahashi, H.; Usami, K.; Hattori, M.; Nishigohri, Y.; Pure Appl. Chem. 1994, 66, 765.

37. Isobe, M.; Uyakul, D.; Goto T.; Tetrahedron Lett. 1988, 44, 1169.

38. Uyakul, D.; Isobe, M.; Goto T.; Bioorg. Chem. 1989, 17, 454.

39. Takahashi, H.; Isobe, M.; Goto, T.; Tetrahedron 1991, 47, 6215.

40. Nakamura, H.; Kishi, Y.; Shimomura, O.; Tetrahedron 1988, 44, 1597.

41. Shimomura, O.; Photochem. Photobiol. 1989, 49, 355.

42. Shimomura, O.; Satoh, S.; Kishi, Y.; J. Biolumin. Chemilumin. 1993, 8, 201.

43. Stevani, C. V.; Baader, W. J.; Quim. Nova 1999, 22, 715.

44. Stevani, C. V.; Silva, S. M.; Baader, W. J.; Eur. J. Org. Chem. 2000, 4037.

45. Albertin, R.; Arribas, M. A. G.; Bastos, E. L.; Roepke, S.; Sakai, P. N.; Sanches, A. M. M.; Stevani, C. V.; Umezu, I. S.; Yu, J.; Baader, W. J.; Quim. Nova 1998, 21, 772.

46. Viviani, V. R.; Bechara, E. J. H.; Química Nova na Escola 2008, 30, 24.

47. Mendes, L. F.; Stevani, C. V.; Environ. Toxicol. Chem. 2010, 29, 320.

48. Mendes, L. F.; Bastos, E. L.; Stevani, C. V.; Environ. Toxicol. Chem. 2010, 29, 2177. 


\section{BIOLUMINESCÊNCIA DE FUNGOS: DISTRIBUIÇÃO, FUNÇÃO E MECANISMO DE EMISSÃO DE LUZ}

\section{Anderson Garbuglio Oliveira}

Departamento de Genética e Evolução, Universidade Federal de São Carlos, Rodovia João Leme dos Santos, km 110, 18052-780 Sorocaba - SP, Brasil

Rodrigo Pimenta Carvalho, Hans Eugene Waldenmaier e Cassius Vinicius Stevani*

Departamento de Química Fundamental, Instituto de Química, Universidade de São Paulo, CP 26077, 05599-970 São Paulo - SP, Brasil

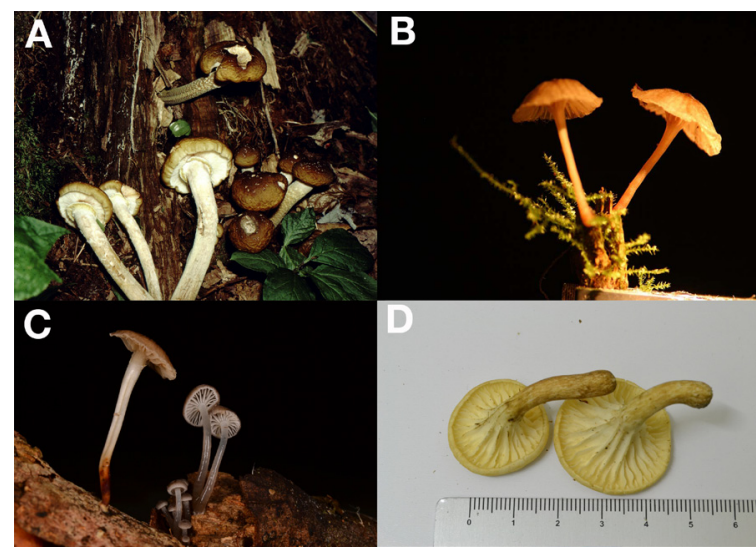

Figura 1S. Corpos de frutificação dos fungos Armillaria mellea (A), Mycena lucentipes (B), Mycena luxaeterna (C) e Neonothopanus gardneri (D), pertencentes às linhagens Armillaria, Lucentipes, Micenoide e Omphalotus, respectivamente

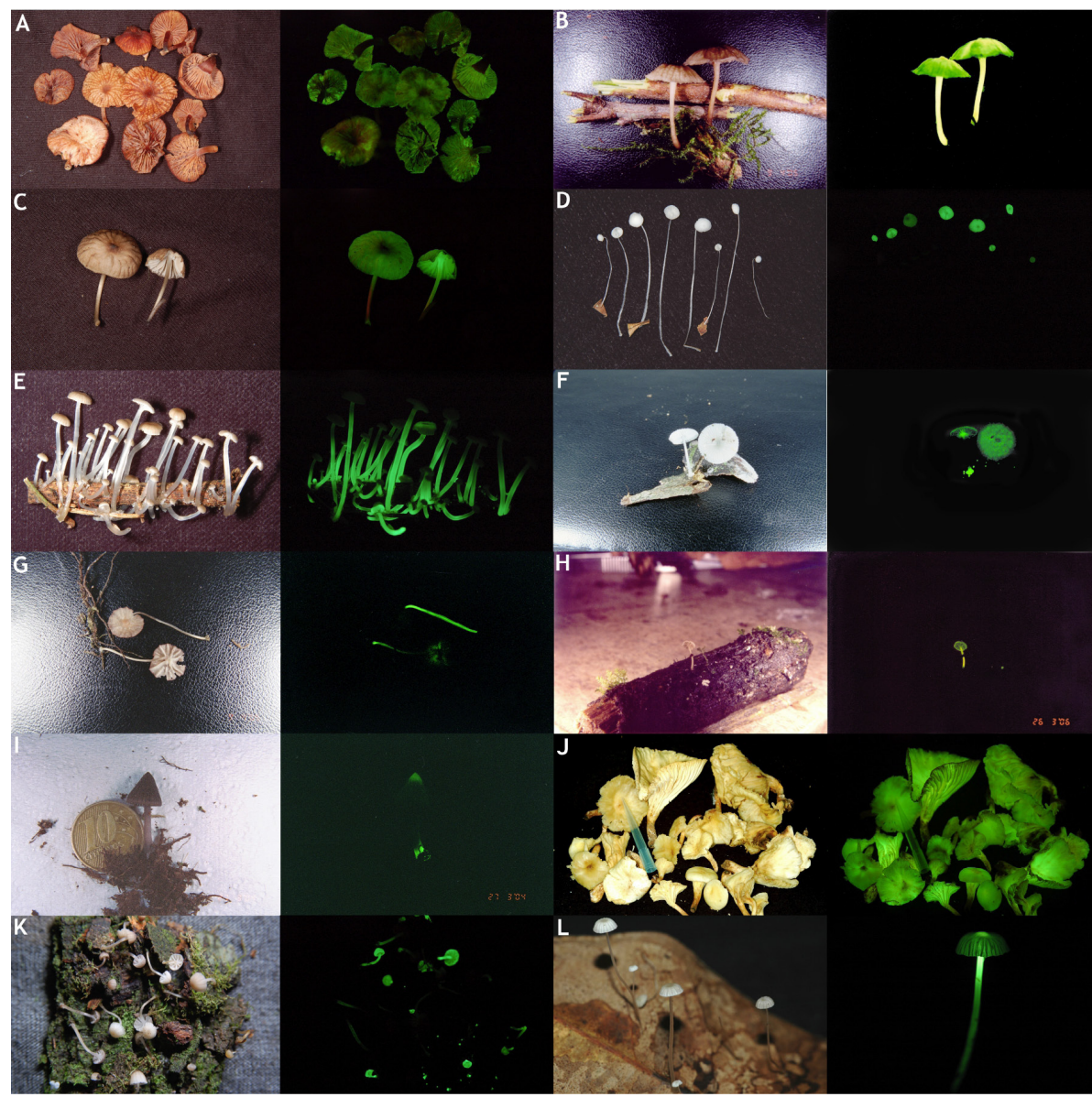

Figura 2S. As 12 espécies de fungos bioluminescentes encontradas no Brasil (A-L), durante os últimos 10 anos (2002-2012). A: Gerronema viridilucens, B: Mycena lucentipes, C: Mycena fera, D: Mycena asterina, E: Mycena luxaeterna, F: Mycena discobasis, G: Mycena singeri, H: Mycena aff. abieticola, I: Mycena sp., J: Neonothopanus gardneri, K: Mycena luxarboricola e L: Mycena lacrimans 